\title{
Electro-thermal and mechanical performance of multi-wall carbon nanotubes buckypapers embedded in fibre reinforced polymer composites for ice protection applications
}

\author{
Francesco Zangrossi ${ }^{a}$, Fang Xu ${ }^{a}$, Nick Warrior ${ }^{a}$, Petros Karapappas ${ }^{b}$, Xianghui Hou ${ }^{a}$ \\ ${ }^{a}$ Faculty of Engineering, University of Nottingham, Nottingham NG7 2RD, UK \\ ${ }^{b}$ Meggitt Airframe Systems Division, Shepshed, Leicestershire, LE12 9EQ, UK
}

Abstract

Several ice protection strategies have been developed to overcome the icing hazards in the aerospace industry. The electro-thermal method is one of the popular approaches to prevent ice accretion and accumulation on aircraft surfaces. Given the increasing requirement of composites on aircraft structures, metal frameworks/fibre reinforced composites have been developed as a de-icing solution for the new generation aircraft. The present work aimed to fabricate self-heating multi-wall carbon nanotubes based composites for ice protection and to study their electro-thermal and mechanical characteristics. Carbon nanotube buckypapers (CNPs) were prepared and embedded in fibre reinforced polymer composites by two methods: pre-preg and resin impregnation. The influence of the carbon nanotube network structure on the mechanical properties and electrical characteristics of the composites was evaluated. Mechanical tests, three-point flexural test and interlaminar shear strength test, demonstrated improved mechanical characteristics of the CNP based composites. De-icing performance of the composites was conducted through a heating test in a climate chamber at $-20^{\circ} \mathrm{C}$. The results indicated that the CNP-based composite is a promising self-heating material candidate for ice protection systems.

Keywords Multi-wall carbon nanotubes, Buckypaper, Electrical resistance, Self-heating composite, De-icing.

\section{Acronyms}

2-CNP: double layer of carbon nanotubes buckypapers

CNP: carbon nanotubes buckypaper

CNT: carbon nanotubes

ILSS: interlaminar shear strength

MWCNT: multi-wall carbon nanotubes

PTFE: polytetrafluorethylene

PV: pre-preg vacuum method

PV-CNP: CNP modified composite with PV method

PP: pre-preg pressure method

PP-CNP: CNP modified composite with PP method

$\mathrm{RV}$ : resin impregnation vacuum method

RV-CNP: CNP modified composite with RV method

RV-ref: reference sample for RV method

$R P$ : resin impregnation pressure method

RP-CNP: CNP modified composite with RP method

RP-ref: reference sample for RV method

RV-2-SCNP: 2 soaked CNP layers in RV composite

RP-2-SCNP: 2 soaked CNP layers in RP composite

SCNP: soaked (in thermosetting resin) carbon nanotubes buckypaper

SEM: scanning electron microscope 


\section{Introduction}

In-flight icing poses a serious hazard to aircraft safety and performance. Ice protection systems are often used to protect aircraft surfaces from ice accretion during the flight or on the ground. Several ice protection strategies to prevent ice accretion have been developed over the years, including heating surfaces with hot air generated from the engine, or electrical heating elements, and inflatable boots supplied by air from the engine or electro-mechanical systems ${ }^{1-}$ 6.

Electro-thermal de-icing constructions are frequently required in the aerospace sector, to prevent ice accumulation and remove the ice from aircraft surfaces during the flight. Typically an electro-thermal structure consists of a metallic framework/element and an inorganic insulator which is normally complicated patterned and heavy ${ }^{5,6}$. Incorporating a traditional metal foil heater technology within a composite construction may lead to a weak layer, especially for inter-laminar shear loads ${ }^{7}$. Recent research works have focused on electrically conducting nanomaterials ${ }^{8-14}$ and found that nanocomposite materials could be incorporated into the composite structure, offering the possibility of heating for ice protection and avoiding structure weakening ${ }^{15-21}$. Coleman et al. ${ }^{20}$ and Wang et al. ${ }^{21}$ studied the intercalation of polymers into porous internal structure of carbon nanotube (CNT) sheets, called buckypapers (CNP). The nanotube buckypapers were prepared by the filtration of CNTs dispersed in water with the aid of a surfactant. The intercalation process was obtained by soaking the nanotube sheets in polymer solutions. The resulting composites showed improved tensile strength ${ }^{20}$ and Young's modulus ${ }^{21}$, indicating a promising approach for the fabrication of nanocomposites with high CNT loading.

There is some recent progress on the fabrication of self-heating composites based on carbon nanotubes for electro-thermal de-icing applications ${ }^{18,19,22,23}$. A thin layer of carbon nanotube buckypaper could be placed between glass fibre fabrics, then infiltrated with a thermosetting resin, and underwent curing reactions. The formed composites exhibited excellent electrical heating performance and stability. However, the simultaneous influence of the conducting CNT buckpaper on the mechanical properties of the composites has yet to be studied. Due to static and dynamic loads suffered by the composite parts during the flight conditions, it is essential to have better understanding on the mechanical behaviours of the CNP-based electro-thermal composite structures. 
In this work, carbon nanotubes buckypapers embedded in fibre reinforced polymer composites have been fabricated by two processing routes and the related electro-thermal and mechanical properties were investigated. CNP layers were produced by filtration technique from CNT suspension and laid up together with pre-preg fabrics. Mechanical tests and the study of heating performance demonstrated that the CNP-based composite is a promising self-heating material candidate for ice protection.

\section{Experimental details}

\subsection{Raw materials}

Multiwalled carbon nanotubes (MWCNTs) from Carbon Nanotubes Plus, Madisonville, USA were used in this work. The nanotubes had an average outer diameter of $5-15 \mathrm{~nm}$ and length of $10-30 \mu \mathrm{m}$. Acetone was purchased by Merck KGaA, Darmstadt, Germany. The thermosetting resin was araldite MY750 supplied by Huntsman, Switzerland and the hardener HX300G/NC was supplied by Robnor Resins, UK. The glass fabric pre-pregs used in this work were DMS435 and CEL100-1. DM435 pre-preg fabrics were supplied by Meggitt Polymers and Composite Airframe Systems Division, Shepshed, UK. The matrix of the DMS435 prepreg fabric was made of resin MY750 mixed with hardener HX300G/NC. The nominal resin content was $50 \mathrm{wt} \%$. CEL100-1 (CEL100-1-G105-4ES-45\%RW-1270mm) was a cyanate ester pre-preg with a 4-harness glass fabric and nominal resin weight content of $45 \%$, provided by SHD Composites, Sleaford, UK.

\subsection{Preparation of buckypapers}

Carbon nanotubes buckypaper (CNP) is a macroscopic aggregate of carbon nanotubes (CNTs). To produce the CNT buckypaper, a water-based suspension of multiwall carbon nanotubes and surfactant (0.1 wt\% Triton X-100) was ultrasonicated for $30 \mathrm{~min}$ and then filtered by a PTFE membrane (Omnipore Membrane Filter PTFE, $1 \mu \mathrm{m}$ pores). The CNP was then detached from the membrane after drying at $35^{\circ} \mathrm{C}$ overnight. The obtained samples were $55 \mathrm{~mm}$ squares.

\subsection{Fabrication of composites with integrated CNP sheets}

\subsubsection{Resin impregnation method}

CNP samples were soaked in 2 grams of epoxy araldite MY750/acetone (100/30 weight ratio) solution for $30 \mathrm{~min}$. Soaked buckypapers (SCNP) were kept under vacuum for $30 \mathrm{~min}$, to allow for the solvent to evaporate and degas the resin at the same time. The buckypapers impregnated with resin were then laminated with pre-preg glass fibres fabric consisting of the same epoxy 
resin. The lay-up configuration was arranged according to the tests to be carried out. The curing cycles in this method are described as below.

$\mathrm{RV}$ (Resin Vacuum) treatment: heating rate $2^{\circ} \mathrm{C} / \mathrm{min}$ and curing at $150^{\circ} \mathrm{C}$ for $1 \mathrm{~h}$ under vacuum. Samples fabricated using this process were named as resin impregnation vacuum samples (RV-CNP).

$\mathrm{RP}$ (Resin Pressure) treatment: heating rate $2^{\circ} \mathrm{C} / \mathrm{min}$ and curing at $150^{\circ} \mathrm{C}$ for $1 \mathrm{~h}$ under 0.4 MPa pressure. Samples from this process were called resin impregnation pressure samples (RP-CNP).

\subsubsection{Pre-preg method}

The buckypapers were laminated between pre-preg plies of CEL 100-1. The lay-up configuration was arranged according to the test to be carried out. The curing cycles in this method are described as below.

PV (Prepreg Vacuum) treatment: heating rate $0.5^{\circ} \mathrm{C} / \mathrm{min}$ and curing at $90^{\circ} \mathrm{C}$ for $6 \mathrm{~h}$ under vacuum. Samples from this process were named as pre-preg vacuum samples (PV-CNP).

PP (Prepreg Pressure) treatment: heating rate $0.5^{\circ} \mathrm{C} / \mathrm{min}$ and curing at $90^{\circ} \mathrm{C}$ for $6 \mathrm{~h}$ under 0.6 MPa pressure. Samples from this process were called pre-preg pressure samples (PP-CNP).

\subsubsection{Lay-up and configuration}

The lay-up details of the different samples are given in Table 1, together with the description of the process conditions. In the lay-up column, 3 or 8 are indicated as the number of pre-preg layers. The number of the utilised pre-preg layers was related to the type of tests. The samples were named accordingly to their fabrication process. For electrical resistance, heating performance and ice protection tests, the samples were $60 \mathrm{~mm}$ x $60 \mathrm{~mm}$ squares. The heating area corresponded to the CNP surface area. The lay-up included 3 pre-preg fabric layers / CNP (or SCNP) / copper electrode / CNP (or SCNP) / 3 pre-preg fabric layers. The electrodes were copper stripes of $5 \mathrm{~mm}$ x $14 \mathrm{~mm}$ x $0.2 \mathrm{~mm}$. Silver paint, from Agar Scientific, was manually applied by a brush in contact with the CNP (or SCNP) which was used to help with electrical resistance reduction at the interface between CNP (or SCNP) and copper electrodes.

For mechanical tests, specimens were machined from $100 \mathrm{~mm}$ x $200 \mathrm{~mm}$ rectangle composite plates, containing 8 pre-preg plies / 2 CNP (or SCNP) / 8 pre-preg plies.

Table 1-Description of sample process conditions and lay-up details

\begin{tabular}{|c|c|c|}
\hline Sample name & Production process & Lay-up \\
\hline
\end{tabular}




\begin{tabular}{|c|c|c|}
\hline RV-CNP & $\begin{array}{c}\text { Resin impregnation method, with curing } \\
\text { condition of } 150{ }^{\circ} \mathrm{C} \text { for } 1 \mathrm{~h} \text { under } \\
\text { vacuum. }\end{array}$ & $\begin{array}{ll}\text { 1- } & \text { Pre-preg layers }(3 \text { or } 8) \\
\text { 2- } & 2 \text { layers of SCNP } \\
\text { 3- } & \text { Pre-preg layers }(3 \text { or } 8)\end{array}$ \\
\hline RP-CNP & $\begin{array}{l}\text { Resin impregnation method, with curing } \\
\text { condition of } 150{ }^{\circ} \mathrm{C} \text { for } 1 \mathrm{~h} \text { under } 0.4 \\
\text { MPa pressure. }\end{array}$ & $\begin{array}{ll}\text { 1- } & \text { Pre-preg layers }(3 \text { or } 8) \\
\text { 2- } & 2 \text { layers of SCNP } \\
\text { 3- } & \text { Pre-preg layers }(3 \text { or } 8)\end{array}$ \\
\hline PV-CNP & $\begin{array}{l}\text { Pre-preg method, with curing condition } \\
\text { of } 90{ }^{\circ} \mathrm{C} \text { for } 6 \mathrm{~h} \text { under vacuum. }\end{array}$ & $\begin{array}{l}\text { 1- } \quad \text { Pre-preg layers }(3 \text { or } 8) \\
\text { 2- } 2 \text { layers of CNP } \\
\text { 3- } \quad \text { Pre-preg layers }(3 \text { or } 8)\end{array}$ \\
\hline PP-CNP & $\begin{array}{l}\text { Pre-preg method, with curing condition } \\
\text { of } 90{ }^{\circ} \mathrm{C} \text { for } 6 \mathrm{~h} \text { under } 0.6 \mathrm{MPa} \text { pressure. }\end{array}$ & $\begin{array}{l}\text { 1- } \quad \text { Pre-preg layers }(3 \text { or } 8) \\
\text { 2- } 2 \text { layers of CNP } \\
\text { 3- } \quad \text { Pre-preg layers }(3 \text { or } 8)\end{array}$ \\
\hline
\end{tabular}

\section{Characterization}

\subsection{Electrical resistance}

The electrical resistance was evaluated by an ohmmeter (Cropico DO4A ohmmeter). The electrical characteristics were calculated using the following equations:

$$
\begin{array}{ll}
\rho=R S / l & \text { Equation (1) } \\
\sigma=1 / \rho & \text { Equation (2) }
\end{array}
$$

where $\rho(\Omega \mathrm{m})$ is the electrical resistivity, $R(\Omega)$ is the electrical resistance, $S\left(\mathrm{~m}^{2}\right)$ is the cross section area of the CNP layer, $l(\mathrm{~m})$ is the tested length of the CNP layer, and $\sigma(\mathrm{S} / \mathrm{m})$ is the calculated electrical conductivity

\subsection{Microstructural characterization}

The microstructural characterization was carried out using a scanning electron microscope (SEM) JSM-7001F by JEOL and a 3D laser scanner microscope Keyence VK-X150K.

\subsection{Heating performance}

The copper electrodes of the sample were connected to a power supply (linear DC bench power supply CSI530S, Circuit Specialists) that provided a constant electrical potential difference of $5 \mathrm{~V}$ in order to analyse the heating performance. The electrical resistance of the sample was calculated by Ohm's law. A thermal imaging camera (FLIR E4, operating in Multi-Spectral Dynamic Imaging mode) was used to measure the sample temperature during the test. The highest surface temperature and the electric current were recorded at regular intervals since the start of the heating process. 


\subsection{De-icing test}

The sample was placed in a sub-ambient environment at $-20^{\circ} \mathrm{C}$ where $100 \mathrm{ml}$ of distilled water were nebulized. A $2 \mathrm{~mm}$ thick ice was formed on the top surface of the sample. The sample was connected to a power supply and a constant potential electrical difference of $5 \mathrm{~V}$ was applied until the ice was fully removed from the surface. The surface temperature and the electric current were regularly registered during the test.

\subsection{Mechanical tests}

Three-point flexure test and interlaminar shear strength (ILSS) were performed. The samples were machined from the composite plates. The samples dimensions were determined by the testing standard, respectively. For three-point flexure test, according to ASTMD790, the size of the samples was $94 \mathrm{~mm} \times 10 \mathrm{~mm}$ x $5 \mathrm{~mm}$; while the CNPs (or SCNPs) were located in the middle of the samples, as represented in Figure 1, where the maximum stress area was localized. For ILSS, the samples dimension was $20 \mathrm{~mm}$ x $10 \mathrm{~mm}$ x $5 \mathrm{~mm}$, while the load range was up to $3 \mathrm{kN}$ and the displacement range was up to $1.5 \mathrm{~mm}$ (CRAIG 100 method $^{24}$ ).

As described previously, the samples for mechanical tests were machined from $100 \mathrm{~mm}$ x 200 $\mathrm{mm}$ rectangle composite plates, containing 8 pre-preg plies / $2 \mathrm{CNP}$ (or SCNP) / 8 pre-preg plies.

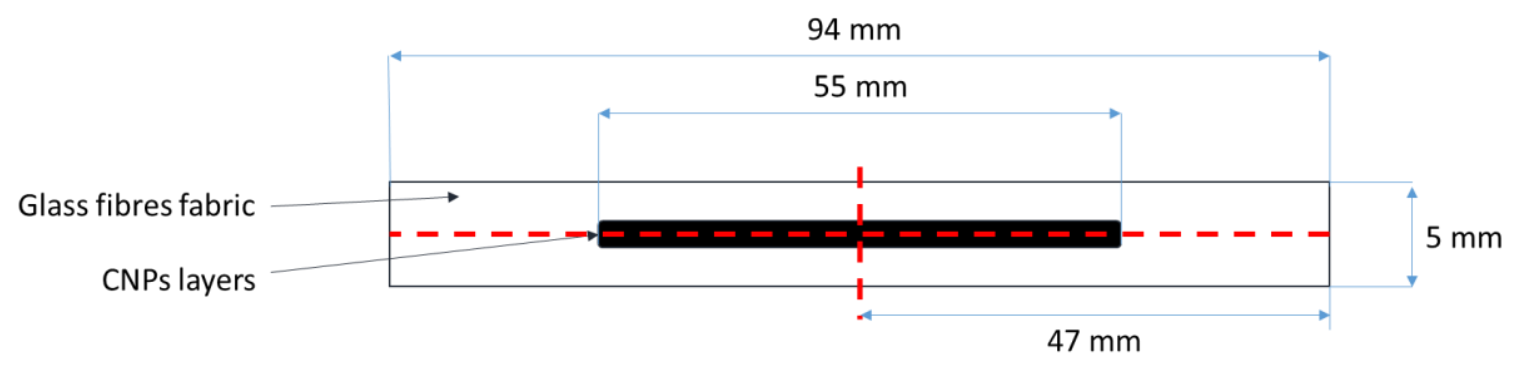

Figure 1 - Schematic diagram of a three-point flexural test sample

\section{Results and discussion}

\subsection{Electrical resistance}

The electrical characteristics of the CNP and composite samples are listed in Table 2. Single and double CNP layers were tested. The average thickness of one CNP layer was around 0.120 $\mathrm{mm}( \pm 0.007 \mathrm{~mm})$. The 2-CNP sample was made by overlapping 2 buckypaper layers on top of each other. The 2-CNP thickness had been calculated by doubling the nominal single layer thickness value. The electrical resistance values of the CNP composites are listed in Table 2, together with standard deviation, average sample thickness, electrical resistivity $\rho$ and 
electrical conductivity $\sigma$. Electrical resistivity values of composite samples in Table 2 are calculated based on the composite thickness. The composite samples were prepared by laying up 2 buckypaper sheets. The electrical characteristics of the composite samples are compared to those of the double CNP (2-CNP) layers.

Table 2 - Electrical characteristics of single (CNP) buckypaper, double (2-CNP) layers of buckypaper and the composite samples

\begin{tabular}{|c|c|c|c|c|c|}
\hline Samples & $\begin{array}{c}\text { Resistance } \\
(\boldsymbol{\Omega})\end{array}$ & $\begin{array}{c}\text { Resistance } \\
\text { St.dev. } \\
(\boldsymbol{\Omega})\end{array}$ & $\begin{array}{c}\text { Thickness } \\
(\mathbf{m m})\end{array}$ & $\begin{array}{c}\boldsymbol{\rho} \\
\left(10^{-3} \boldsymbol{\Omega} \mathbf{~ m}\right)\end{array}$ & $\begin{array}{c}\boldsymbol{\sigma} \\
(\mathbf{S} / \mathbf{m})\end{array}$ \\
\hline Single CNP & 5.5 & 0.5 & 0.12 & 0.661 & 1513.2 \\
\hline 2-CNP & 2.4 & 0.6 & 0.24 & 0.574 & 1741.7 \\
\hline RV-CNP & 3.8 & 0.6 & 2.80 & 10.6 & 94.0 \\
\hline RP-CNP & 3.7 & 0.2 & 2.40 & 8.9 & 112.6 \\
\hline PV-CNP & 1.8 & 0.3 & 1.00 & 1.8 & 555.6 \\
\hline PP-CNP & 1.7 & 0.2 & 1.00 & 1.7 & 588.2 \\
\hline
\end{tabular}

MWCNTs are randomly distributed and contact with each other, forming the CNP conductive network (Figure 2). The electrical conduction in the composite samples is attributed to the combination of MWCNTs and their junctions. The electrical resistance along a carbon nanotube is much lower than the junction resistance so that the CNP network can be illustrated by a series of resistors consisting of compactly connected nanotubes ${ }^{18,19,25,26}$. The contacts between the CNTs create the pathways for the electrical current to flow through. Despite the insulating characteristics of the epoxy around the MWCNT bundles, the electrical conductivity of 2-CNP does not have a significant variation, compared with the RV-CNP and the RP-CNP samples. This means that the conducting pathways of the MWCNT network are not significantly affected by the insulating resin. Pre-preg samples have approximately $50 \%$ lower electrical resistance compared with the samples produced by resin impregnation method. These values are slightly lower than the electrical resistance of 2-CNP samples. The composite fabrication process would affect the electrical resistance except in the pre-preg method. This could be due to the low amount of resin involved in the process, coming from the pre-preg fabric. Moreover the buckypapers used in pre-preg method were not previously soaked in any thermosetting resin. The amount of resin coming from the pre-preg fabric was not enough to completely impregnate the CNTs sheets and to affect/increase their electrical resistance. The lower electrical resistance values of PP-CNP and PV-CNP samples could be due to the silver paint applied on the electrodes surface. The paint helped to increase the electrical conductivity locally at the interface between the CNP and the electrodes. 


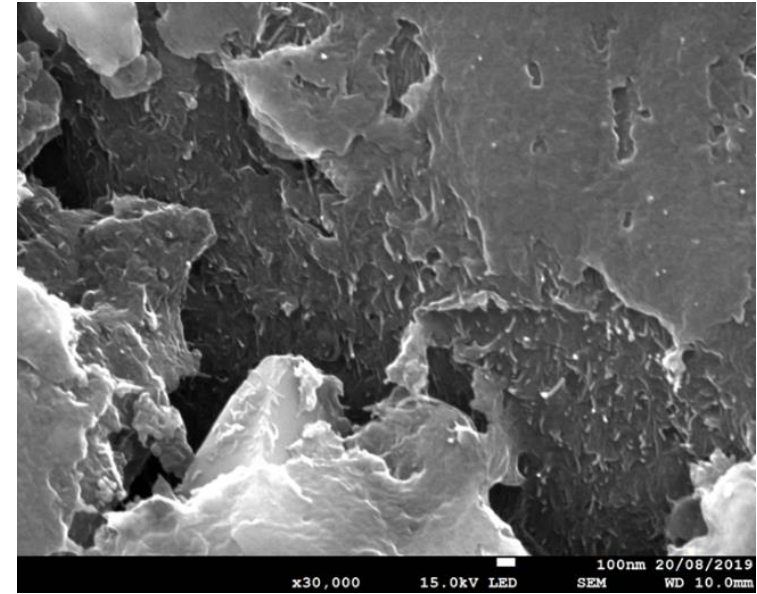

a)

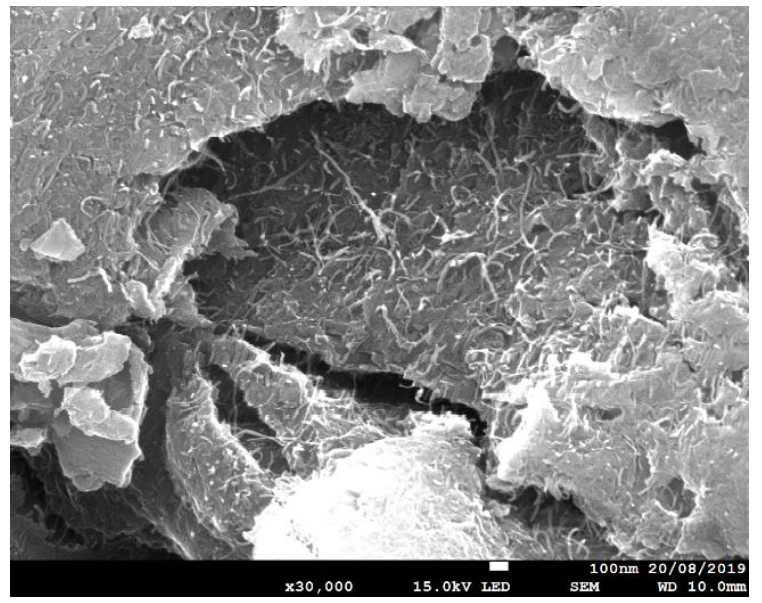

b)

Figure 2 - SEM images of soaked buckypaper after the curing cycle: a) RV sample; b) RP sample

The low standard deviations (Table 2) indicate that the pressure helped to obtain a more repeatable result in the resin impregnation method. The electrical resistances of RP-CNP and RV-CNP samples are higher than that of the pure double CNPs layers. This is probably due to the resin electrical insulating characteristics and the involved resin reduced the direct contacts of CNTs.

During the machining of the specimens for morphological analysis and mechanical tests, delamination was observed in the samples fabricated with the pre-preg method (Figure 3a and 3b). For the PV-CNP (Figure 3a) and PP-CNP (Figure 3b) samples, delamination occurred along the interface between the two CNPs. This was likely happened because the resin did not fully impregnate the porous CNP and thus proper bonding was not formed between the layers. Due to the delamination, PP-CNP and PV-CNP samples had not been selected for further analysis and tests.

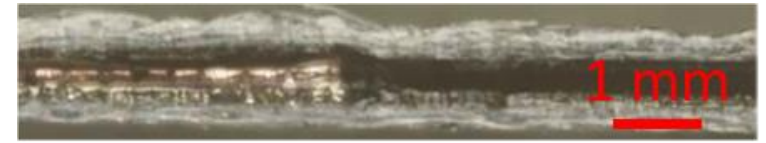

a)

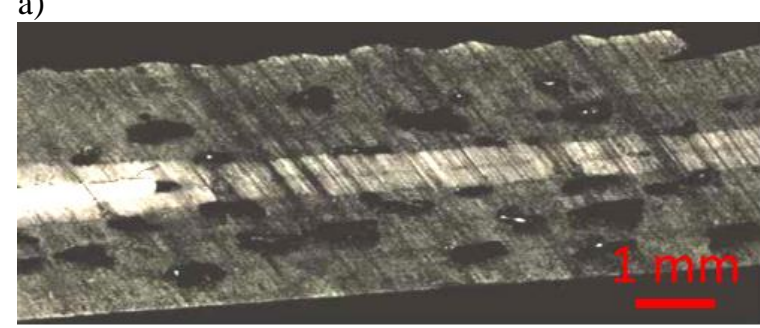

c)

Figure 3 - Cross section images of: a) PV-CNP sample; b) PP-CNP sample; c) RV-CNP sample; d) RP-CNP sample.

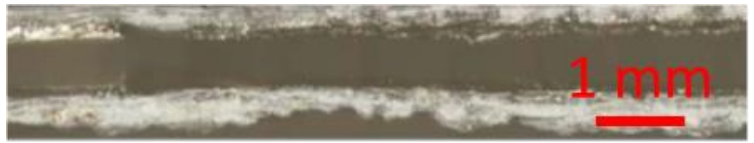

b)

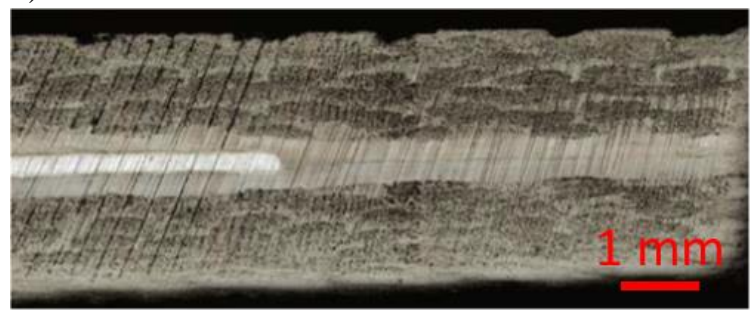

d) 
The CNT weight percentage, in the RV-CNP and RP-CNP composite samples, has been calculated and listed in Table 3, while the weight of the copper electrodes has been subtracted. The average weight values for RV and RP samples are $13.0 \mathrm{~g}$ and $14.0 \mathrm{~g}$, respectively. Considering that in each sample there are two CNP buckypaper sheets, the CNP weight percentage in both the composites is less than $1 \mathrm{wt} \%$.

Table 3 - Buckypaper weight percentage in the composite structure

\begin{tabular}{|c|c|c|c|}
\hline Sample & $\begin{array}{c}\text { Composite } \\
\text { Weight } \\
\text { (g) }\end{array}$ & $\begin{array}{c}\text { Weight } \\
\text { St.dev. } \\
(\mathbf{g})\end{array}$ & $\begin{array}{c}\text { CNT } \\
\text { content } \\
\text { (wt } \%)\end{array}$ \\
\hline RV-CNP & 13.0 & 0.5 & 0.8 \\
\hline RP-CNP & 14.0 & 0.3 & 0.7 \\
\hline
\end{tabular}

Thickness analysis of RV-CNP and RP-CNP samples are shown in Figure 4 and the thickness values are listed in Table 4. RV-2-SCNP and RP-2-SCNP refer to the soaked buckypapers (SCNP) layers used in resin impregnation methods; the number 2 means that two CNPs sheets have been laid-up. In both RV and RP method, the thickness of RV-2-SCNP and RP-2-SCNP (Table 4) are higher than the 2-CNP thickness (Table 2). The resin impregnation causes the thickness increase and thus the electrical resistance increase. Because of insulating properties of the resins, the conductive area is limited to the CNPs area. In order to calculate the electrical resistivity more accurately (Table 4), the heating element cross section (Figure 4) has been analysed.

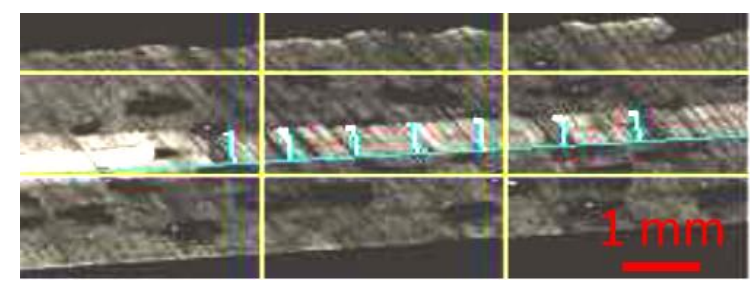

a)

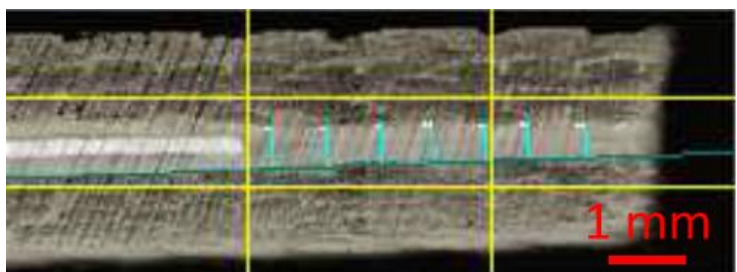

b)

Figure 4 - Thickness analysis for: a) RV-CNP sample; b) RP-CNP sample. The light blue vertical line indicates where the thickness has been measured.

Table 4 - Electrical characteristics of CNP soaked in thermosetting resin

\begin{tabular}{|c|c|c|c|c|}
\hline Sample & $\begin{array}{c}\text { Resistance } \\
(\boldsymbol{\Omega})\end{array}$ & $\begin{array}{c}\text { Thickness } \\
(\mathbf{m m})\end{array}$ & $\begin{array}{c}\boldsymbol{\rho} \\
\left(10^{-\mathbf{3}} \boldsymbol{\Omega} \mathbf{~ m}\right)\end{array}$ & $\begin{array}{c}\boldsymbol{\sigma} \\
(\mathbf{S} / \mathbf{m})\end{array}$ \\
\hline RV-2-SCNP & 3.8 & 0.421 & 1.6 & 625.1 \\
\hline RP-2-SCNP & 3.7 & 0.408 & 1.5 & 662.4 \\
\hline
\end{tabular}

In existing reports, CNTs had been mixed with polymer resins to produce electrical conducting nanocomposites, but the resulting structures often exhibited relatively low electrical conductivity (less than $1 \mathrm{~S} / \mathrm{m}$ ), as the impregnation of polymer matrices decreased the continuity of the CNT conducting network for the current flow ${ }^{26-29}$. The CNP based composites 
in this study have demonstrated higher electrical conductivity thanks to the better integration of the formed CNTs conducting network, in which the negative impact from the polymeric resin would be minimized.

\subsection{Heating performance}

In Figure 5 two thermal images show the temperature distribution on the surfaces of the RVCNP sample (Figure 5a) and the RP-CNP sample (Figure 5b), respectively. Both images show an even heat distribution on the sample surface, between the two electrodes. The aforementioned fact indicates that the current flow is constant over the entire surface.
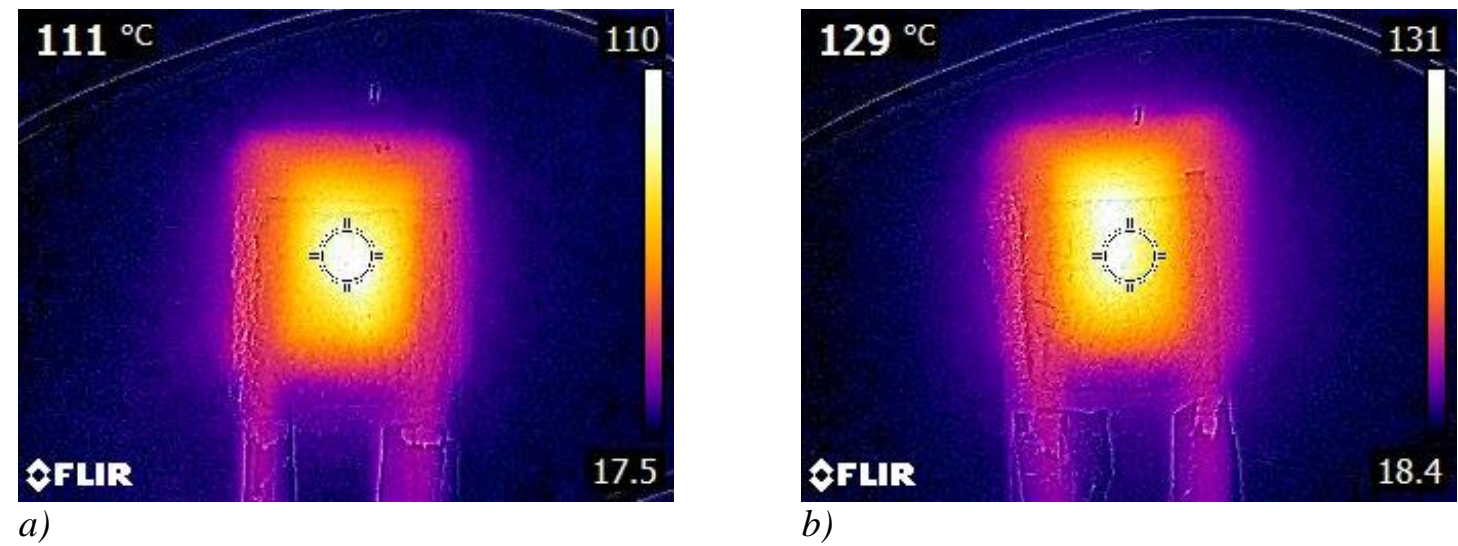

Figure 5 - Thermal images of: a) RV-CNP sample; b) RP-CNP sample

Figure 6 and Figure 7 plot the changes of temperature T, current I and resistance R of the different samples during the heat performance test. The standard deviations are indicated in the curves. In general, the standard deviations of RP samples is smaller than those of the RV samples. It can be noticed that RP samples have much constant values than RV samples. It is likely that the pressure during the curing process helps to establish and stabilise the electrical paths and resistance. All the studied curves can be divided in three stages. There is a linear increase of the temperature (first), followed by a decreasing of temperature rising speed (second) until the temperature reach a stable value (third).

The power consumption values of composite samples during the heating test are listed in Table 5 and Table 6. Power density values were around $2 \mathrm{~kW} / \mathrm{m}^{2}$ and the maximum reached temperatures were higher than $100^{\circ} \mathrm{C}$. For de-icing systems, lower temperatures as well as lower power densities can be used to avoid possible thermal damage of the composite structure. The sample with the lowest electrical resistance reached the highest power density value $(2.4$ $\mathrm{kW} / \mathrm{m}^{2}$ for $\mathrm{RV}$ class and $2.2 \mathrm{~kW} / \mathrm{m}^{2}$ for RP class, respectively) and the highest temperature $\left(133^{\circ} \mathrm{C}\right.$ for $\mathrm{RV}$ class and $132^{\circ} \mathrm{C}$ for RP class, respectively). 
Table 5 - Heating performance and testing characteristics of $R V$-samples

\begin{tabular}{|c|c|c|c|c|c|}
\hline Sample & $\begin{array}{c}\text { Current } \\
(\mathbf{A})\end{array}$ & $\begin{array}{c}\text { Resistance } \\
(\mathbf{\Omega})\end{array}$ & $\begin{array}{c}\text { Power } \\
(\mathbf{W})\end{array}$ & $\begin{array}{c}\text { Power } \\
\mathbf{d e n s i t y} \\
\left(\mathbf{k W} / \mathbf{m}^{\mathbf{2}}\right)\end{array}$ & $\begin{array}{c}\mathbf{T}_{\text {MAX }} \\
\left({ }^{\circ} \mathbf{C}\right)\end{array}$ \\
\hline 1 & 1.0 & 4.9 & 5.2 & 1.7 & 111 \\
\hline 2 & 1.3 & 3.9 & 6.4 & 2.1 & 120 \\
\hline 3 & 1.4 & 3.5 & 7.1 & 2.4 & 133 \\
\hline
\end{tabular}

Table 6 - Heating performance and testing characteristics of RP-samples

\begin{tabular}{|c|c|c|c|c|c|}
\hline Sample & $\begin{array}{c}\text { Current } \\
(\mathbf{A})\end{array}$ & $\begin{array}{c}\text { Resistance } \\
(\boldsymbol{\Omega})\end{array}$ & $\begin{array}{c}\text { Power } \\
(\mathbf{W})\end{array}$ & $\begin{array}{c}\text { Power } \\
\mathbf{d e n s i t y} \\
\left(\mathbf{k W} / \mathbf{m}^{2}\right)\end{array}$ & $\begin{array}{c}\mathbf{T}_{\text {MAX }} \\
\left({ }^{\circ} \mathbf{C}\right)\end{array}$ \\
\hline 1 & 1.2 & 4.0 & 6.2 & 2.1 & 118 \\
\hline 2 & 1.3 & 3.7 & 6.7 & 2.2 & 132 \\
\hline 3 & 1.3 & 3.8 & 6.7 & 2.2 & 130 \\
\hline
\end{tabular}




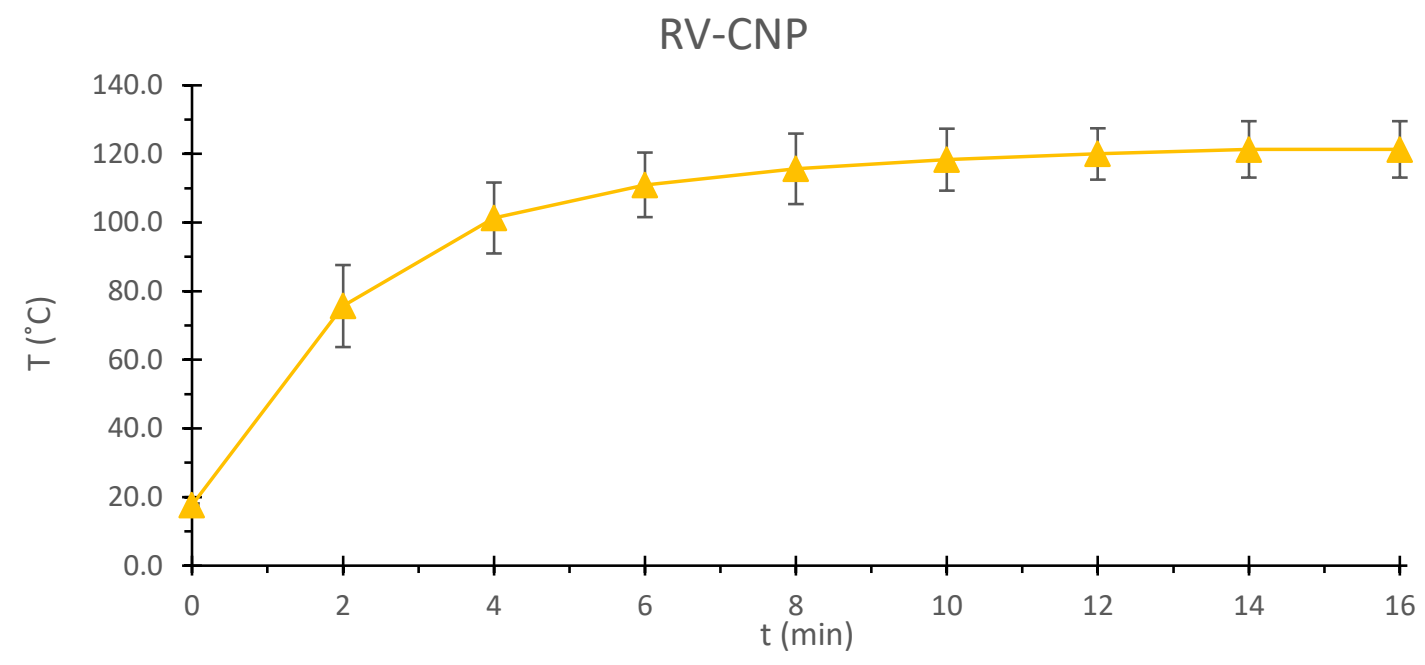

a)

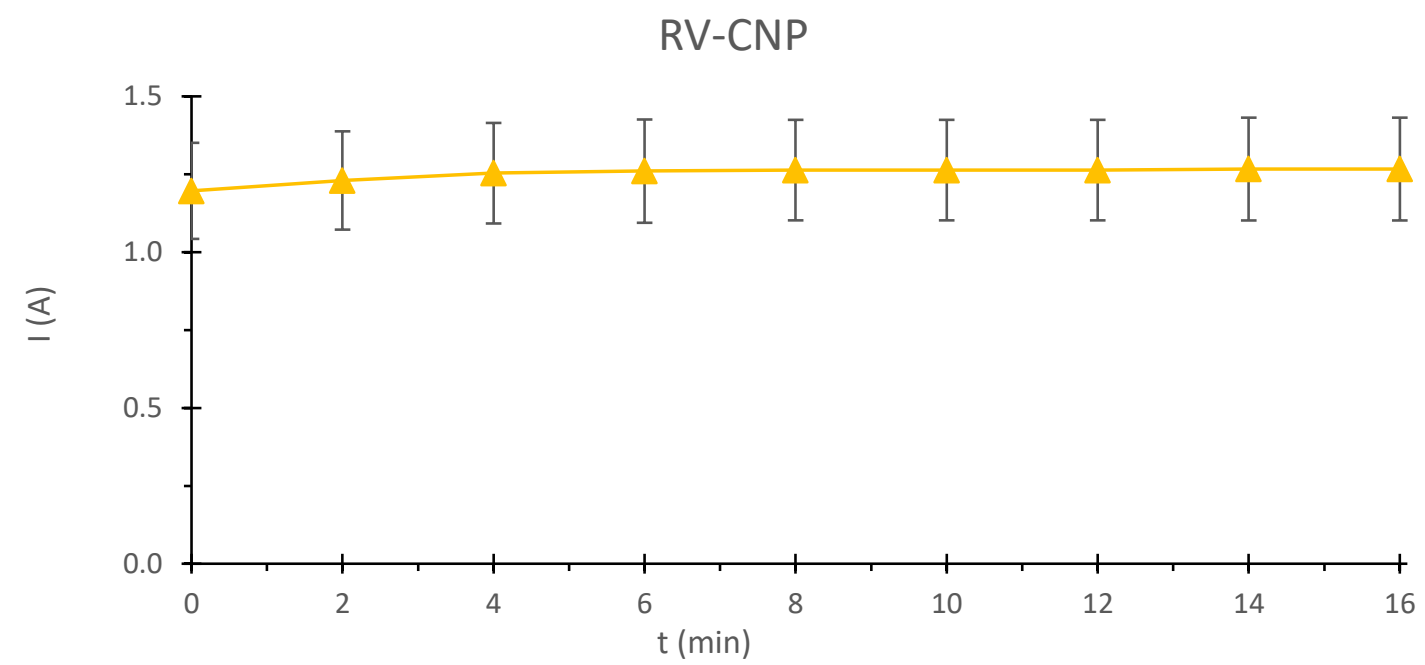

b)

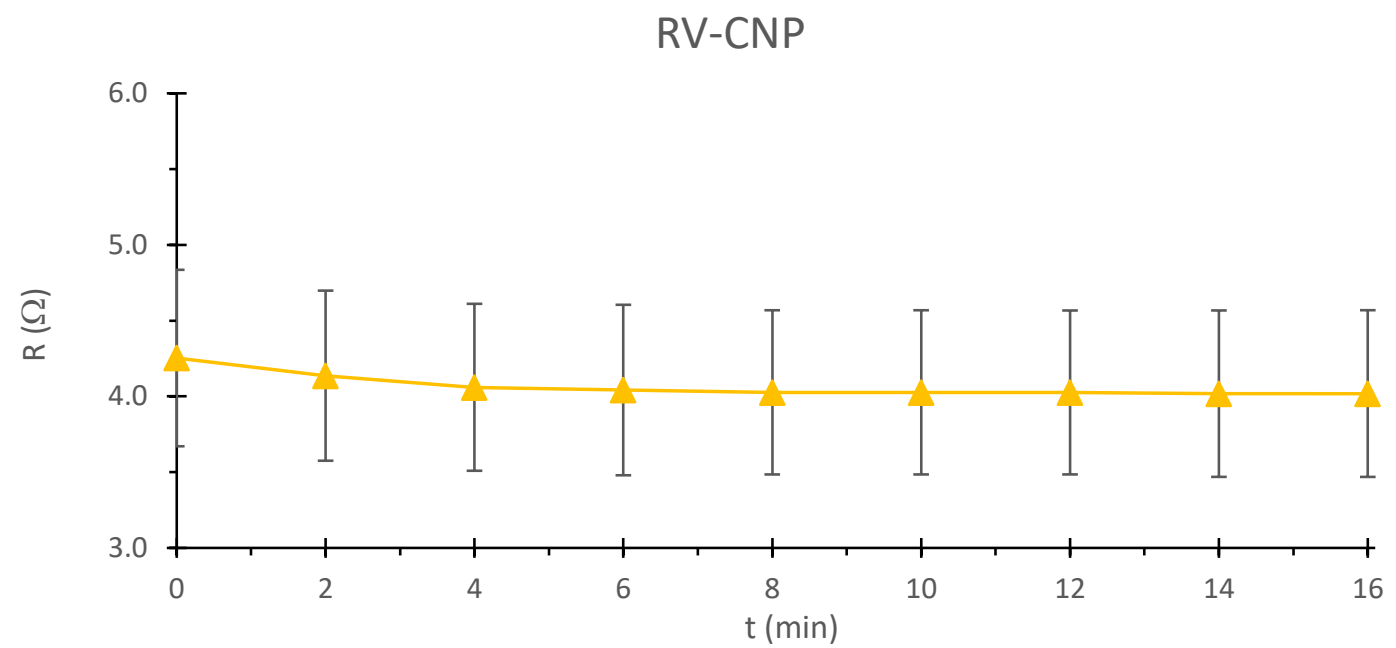

c)

Figure 6 - Curves of RV-samples characteristics registered during the heating performance test: a) temperature $T ; b)$ current $I ; c)$ resistance $R$. The orange lines represent the average value of the respective characteristic. 


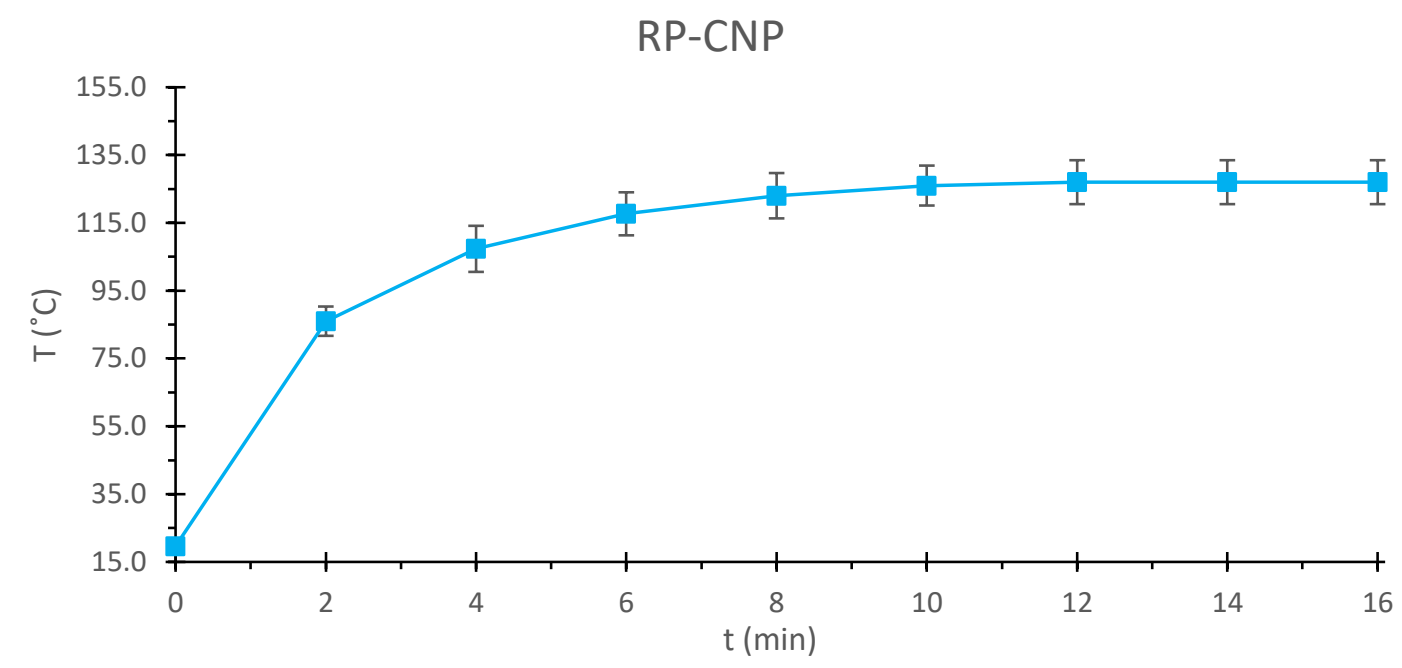

a)

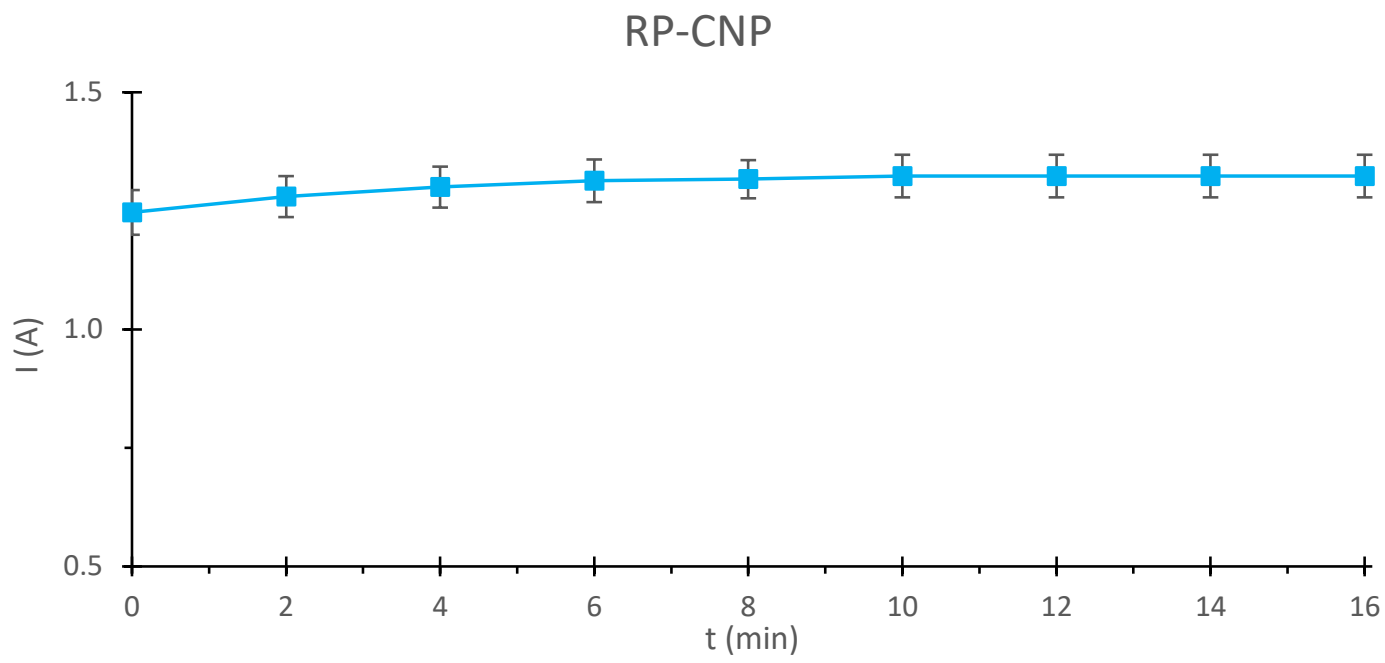

b)

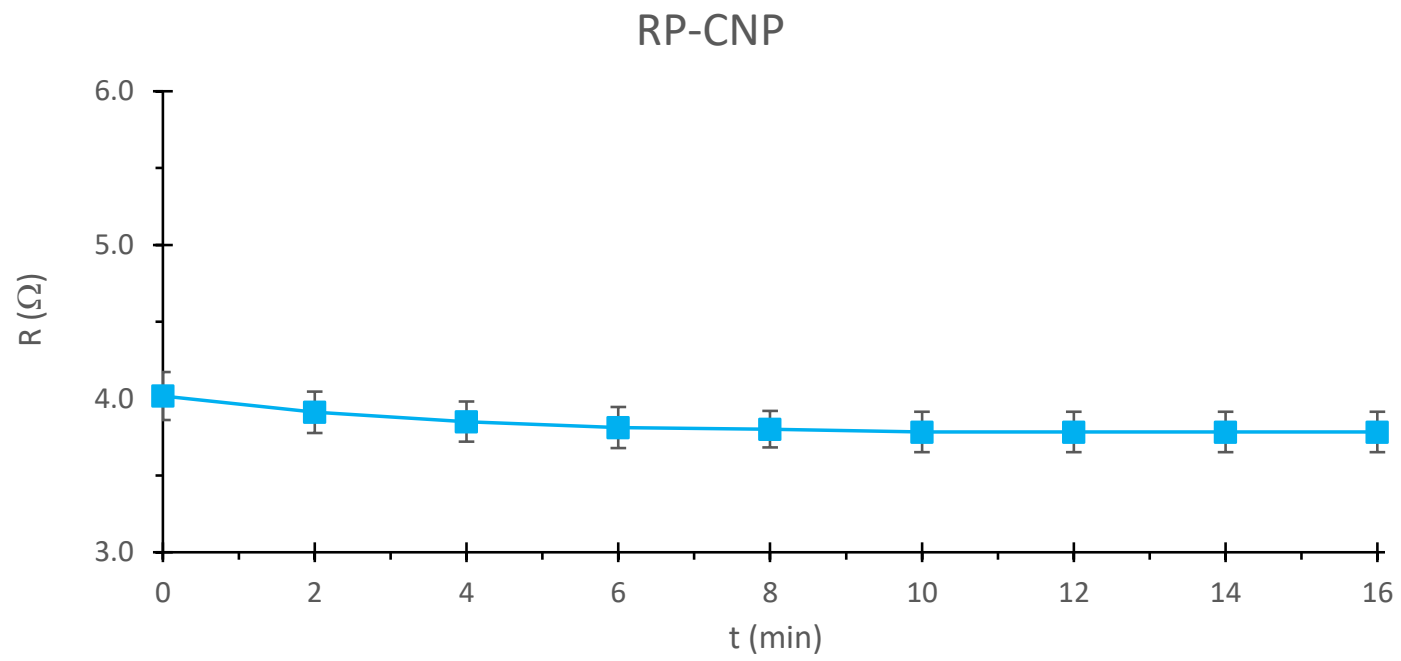

c)

Figure 7 - Curves of RP-samples characteristics registered during the heating performance test: a) temperature $T ; b$ ) current $I ; c)$ resistance $R$. The light blue lines represent the average value of the respective characteristic. 


\subsection{De-icing test}

Figure 8 shows the sample covered by rime ice in a cold environment at $-20^{\circ} \mathrm{C}$ (Figure $8 \mathrm{a}$ ) and the sample after 120s electro-thermal heating (Figure 8b). Due to the Joule effect the temperature rises where the electrical current flows as the heat distribution indicated in Figure 8d. This test simulates the ice protection system working in the electro-thermal de-icing configuration.

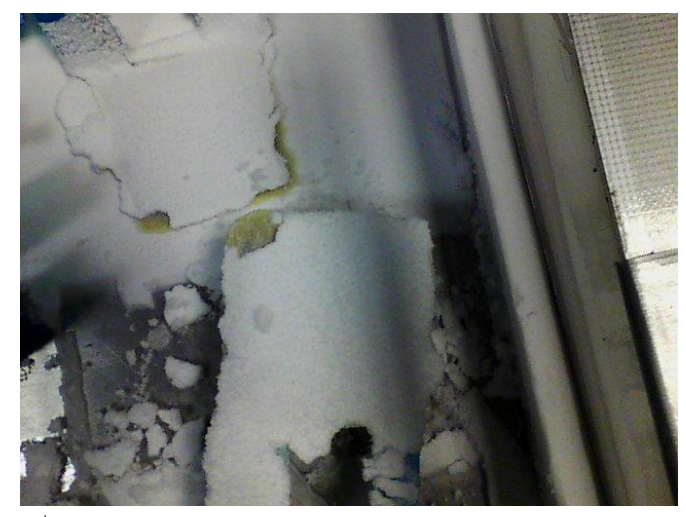

a)

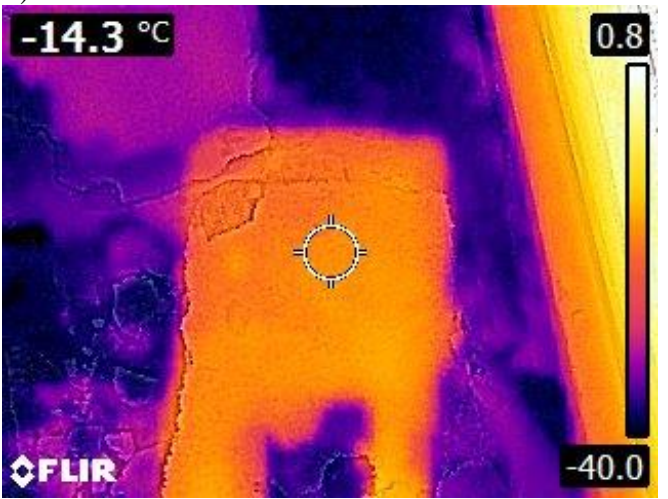

c)

Figure 8 - Photos and thermal images of a RV sample during the de-icing test in the cold environment: $a, c)$ at the beginning of the heating; $b, d)$ after 120s heating

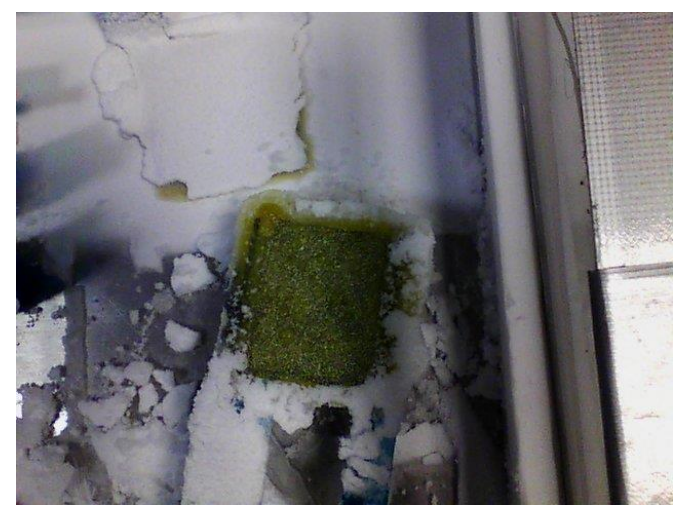

b)

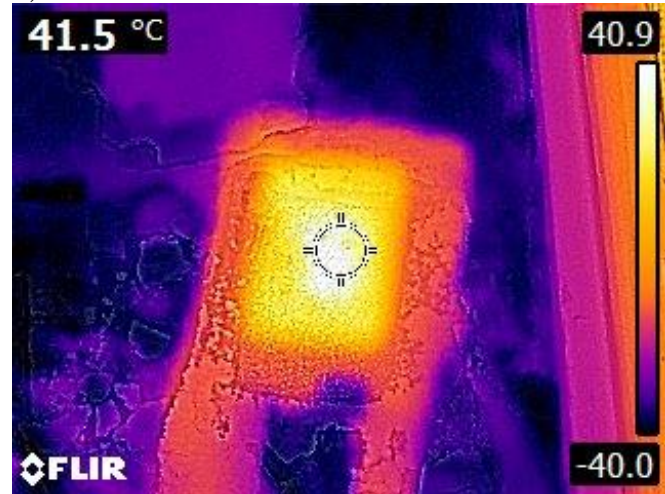

d)

Figure 9 show the temperature $(\mathrm{T})$ changes of different samples during the de-icing test. The ice melting time was considered as the moment, after the beginning of the test, in which the sample average temperature rose over $0^{\circ} \mathrm{C}$. The ice melting time range of RV samples was between $30 \mathrm{~s}$ and $60 \mathrm{~s}$, while for the RP samples the ice melting time range was between $30 \mathrm{~s}$ and 40s. When the ice was melted, the temperature of the RV and RP samples rose at $\sim 0.8^{\circ} \mathrm{C} / \mathrm{s}$. It can be noticed that the temperature deviation of RP samples are narrower than those for RV samples, as indicated in the heating performance test.

In Table 7 the power consumption and power densities of de-icing are listed. In all the cases, the ice on the samples was completely removed after 120 s. It was noticed that, at the end of the experiment, the temperature was still rising. Lower voltages could be used, causing the increase 
of the ice melting time, but the working temperature would be lower than $100^{\circ} \mathrm{C}$ to avoid the possible thermal damage of the composite structure. Power density values around $2 \mathrm{~kW} / \mathrm{m}^{2}$ were within the range of the reported values ${ }^{18,19,22}$.

Table 7 - De-icing tests characteristics of RV and RP samples

\begin{tabular}{|c|c|c|c|c|}
\hline Sample & $\begin{array}{c}\text { Power } \\
(\mathbf{W})\end{array}$ & $\begin{array}{c}\text { St.dev. } \\
(\mathbf{W})\end{array}$ & $\begin{array}{c}\text { Power } \\
\text { density } \\
\left(\mathbf{k W} / \mathbf{m}^{\mathbf{2}}\right)\end{array}$ & $\begin{array}{c}\text { St.dev. } \\
\left(\mathbf{k W} / \mathbf{m}^{\mathbf{2}}\right)\end{array}$ \\
\hline RV-CNP & 6.0 & 0.7 & 1.99 & 0.25 \\
\hline RP-CNP & 6.5 & 0.4 & 2.14 & 0.14 \\
\hline
\end{tabular}

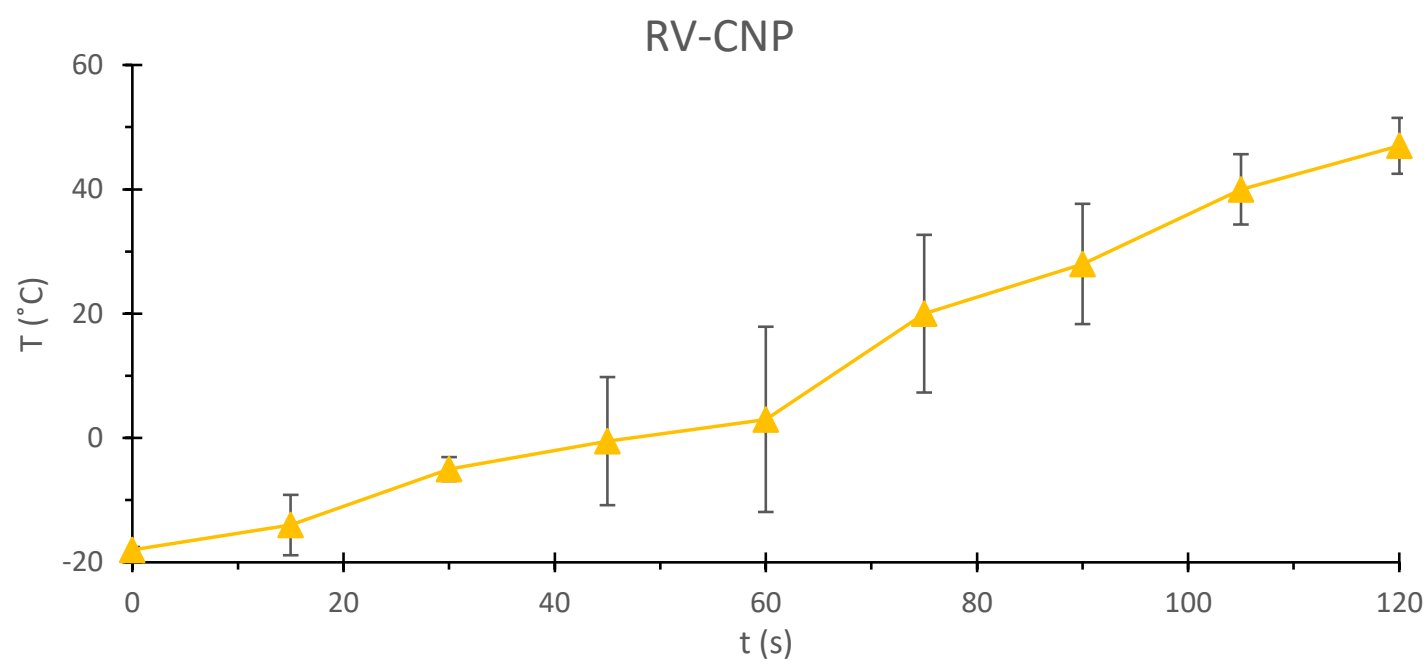

a)

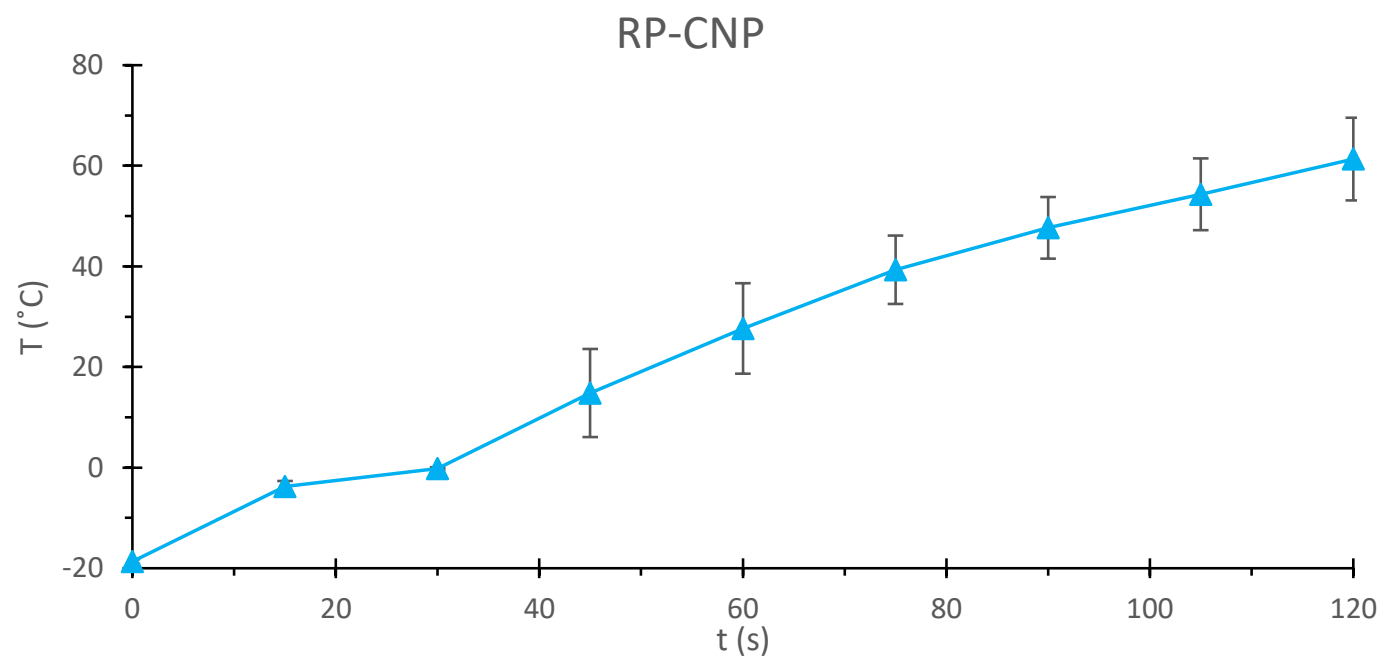

b)

Figure 9 - Increase of temperature during the de-icing test: a) RV samples; b) RP samples. 


\subsection{Mechanical tests}

The details of samples for mechanical tests can be found in Table 1. CNP composites produced with RV treatment are referred as RV-CNP; while the RP-CNP designation was assigned to CNP composites produced with RP treatment. Reference samples were produced with lay-up of just pre-preg fabrics and they were named RV-ref for RV treatment and RP-ref for RP treatment, respectively. Flexural test results are listed in Table 8. The RP samples have higher fracture stress value than the RV ones. . The pressure during curing cycle is considered as the main reason of the difference. The RP-CNP samples also demonstrated higher (about $\sim 9 \%$ more) fracture stress than RP-ref, indicating that the buckypapers acted like a reinforcement layer in the composite structure. However, for RV samples, their fracture stress is lower than that of RV-ref. Due to the high defect concentration (as visible in Figure 10c), it is not possible to determine if the buckypapers acted as defect source weakening the RV-CNP samples.

Table 8-Three-point flexural tests results.

\begin{tabular}{|c|c|c|c|c|c|}
\hline Sample & $\begin{array}{c}\text { Fracture } \\
\text { Stress } \\
(\mathrm{MPa}) \\
\end{array}$ & $\begin{array}{l}\text { St. Dev. } \\
\text { (MPa) }\end{array}$ & $\begin{array}{c}\text { Young's } \\
\text { modulus } \\
(\text { GPa }) \\
\end{array}$ & $\begin{array}{c}\text { St. Dev. } \\
\text { (GPa) }\end{array}$ & $\begin{array}{c}\begin{array}{c}\text { CNT } \\
\text { content }\end{array} \\
(w t \%)\end{array}$ \\
\hline RP-CNP & 353.3 & 13.7 & 16.3 & 0.6 & 0.7 \\
\hline RP-ref & 321.0 & 15.2 & 14.1 & 0.3 & - \\
\hline RV-CNP & 231.6 & 10.1 & 11.4 & 0.6 & 0.8 \\
\hline RV-ref & 283.6 & 9.3 & 12.8 & 0.4 & - \\
\hline
\end{tabular}

Considering the high defect concentration, RV method (Figure 10a and 10c) seems not to be an ideal process for the fabrication of the self-heating composites. To avoid the formation of porosity, some pressure should be applied during the curing cycle of the thermosetting system (resin/hardener), as confirmed from the porosity-free structures of RP samples (Figure 10b and 10d). RP-ref (Figure 10b) and RP-CNP (Figure 10d) show similar fracture morphology. This indicates that the SCNP layer did not cause obvious change in the fracture mechanism. Figure $10 \mathrm{~d}$ shows that the crack propagated in the SCNP layer. This could explain the higher fracture stress of the RP-CNP samples. 


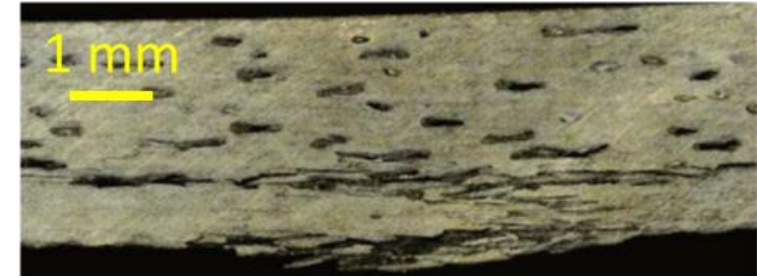

a)

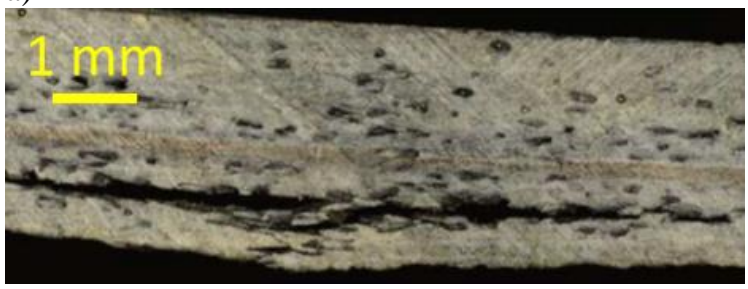

c)

Figure 10 - Three-point flexural tested samples: a) RV-ref sample; b) RP-ref sample; c) RV-CNP sample; d) RP-CNP sample

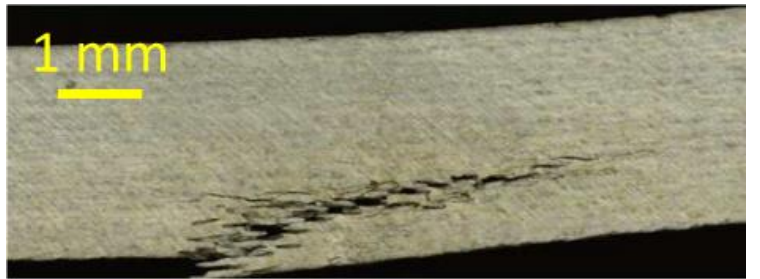

b)

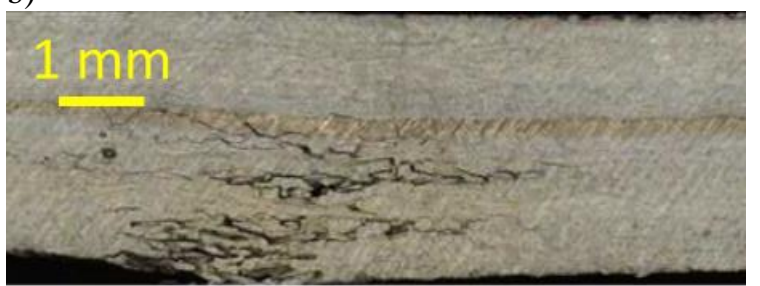

d)

ILSS results are listed in Table 9. The RP-CNP and RP-ref samples have slightly lower values than RP-ref. The buckypaper did not bring significant changes to this characteristic. ILSS average value of RV-CNP is lower than RV-ref ( 30\% lower). A typical RV-CNP fracture surface is given in Figure 11. The buckypapers have probably weakened the structure, acting as a defect affecting thus the interface between. In RV-CNP samples, the crack propagated along the interface between the two CNP sheets. The buckypapers interface seems to be a weak point for the RV-CNP samples. This result has confirmed that the CNP layer acted as a defect in the RV-CNP samples. The pressure during curing cycle would be the key reason of the different mechanical responses between RP-CNP and RV-CNP. The use of pressure enhanced the interface bond between the CNP sheets. The above results further highlight that the RV treatment may not be appropriate for manufacturing of the self-heating composites.

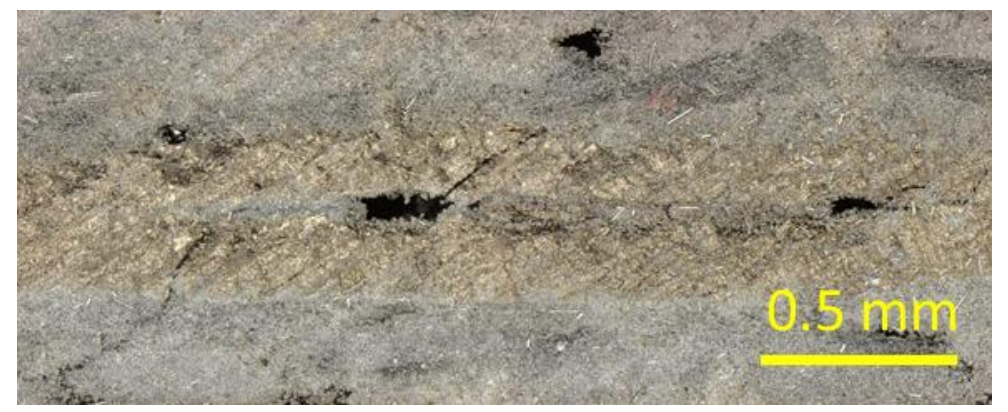

Figure 11 - Laser microscope image of ILSS RV sample with crack between two SCNP sheets

Table 9 - Interlaminar Shear Strength results of the studied composite structures

\begin{tabular}{|c|c|c|c|}
\hline Sample & $\begin{array}{c}\text { ILS } \\
\text { Strength } \\
\text { (MPa) }\end{array}$ & $\begin{array}{c}\text { St. Dev. } \\
\text { (MPa) }\end{array}$ & $\begin{array}{c}\text { CNT } \\
\text { content } \\
(w t \%)\end{array}$ \\
\hline RP-CNP & 45.0 & 2.2 & 0.7 \\
\hline
\end{tabular}




\begin{tabular}{|c|c|c|c|} 
RP-ref & 48.1 & 1.1 & - \\
\hline RV-CNP & 27.5 & 0.8 & 0.8 \\
\hline RV-ref & 38.1 & 2.1 & - \\
\hline
\end{tabular}

In Figure 12 and Figure 13, the ILSS t stress-strain curves of the RV and RP samples are depicted. Each test includes five specimens. RP samples reach higher stress values than RV ones, thanks to their better microstructural characteristics. The small standard deviation of the RP samples indicates a rather homogeneous composite structure even after the incorporation of the CNPs. As discussed in the previous session, the pressure, hence better consolidation, during the curing process would be the main reason of better mechanical performance of RP samples.

The gaps on the RV-CNP curves (for $\varepsilon>12.5 \%$, Figure 12a) are caused by the fractures that were created on the sample during the test (example in Figure 11). It can be noticed from the curves that all the RV-CNP samples have been damaged during the test. This is a further proof that RV is not an ideal method for the fabrication of the CNP based self-heating composites.

The ILSS results indicate that RP-CNP and RP-ref have similar stress-strain behaviour, see Figure 13. The regular/linear trend of the curves indicates that the specimens have not been damaged during the test. The RP samples (CNP and ref) have been able to withstand up to $3 \mathrm{kN}$ interlaminar shear load. In Figure 13, the average strain value at the end of the test is between 15\% 20\% for RP-CNP samples and between 20\% 25\% for RP-ref, respectively. These results indicate a more rigid mechanical response for RP-CNP samples.

From the mechanical tests results for the RP-CNP specimens, it can be deducted that the CNPs do not cause a deterioration of the mechanical characteristics of the composite structure. Moreover, the flexural tests show a slight improvement of the fracture strength, about $10 \%$ higher. These results indicate that the RP method is appropriate for the fabrication of the CNP based self-heating composite. 


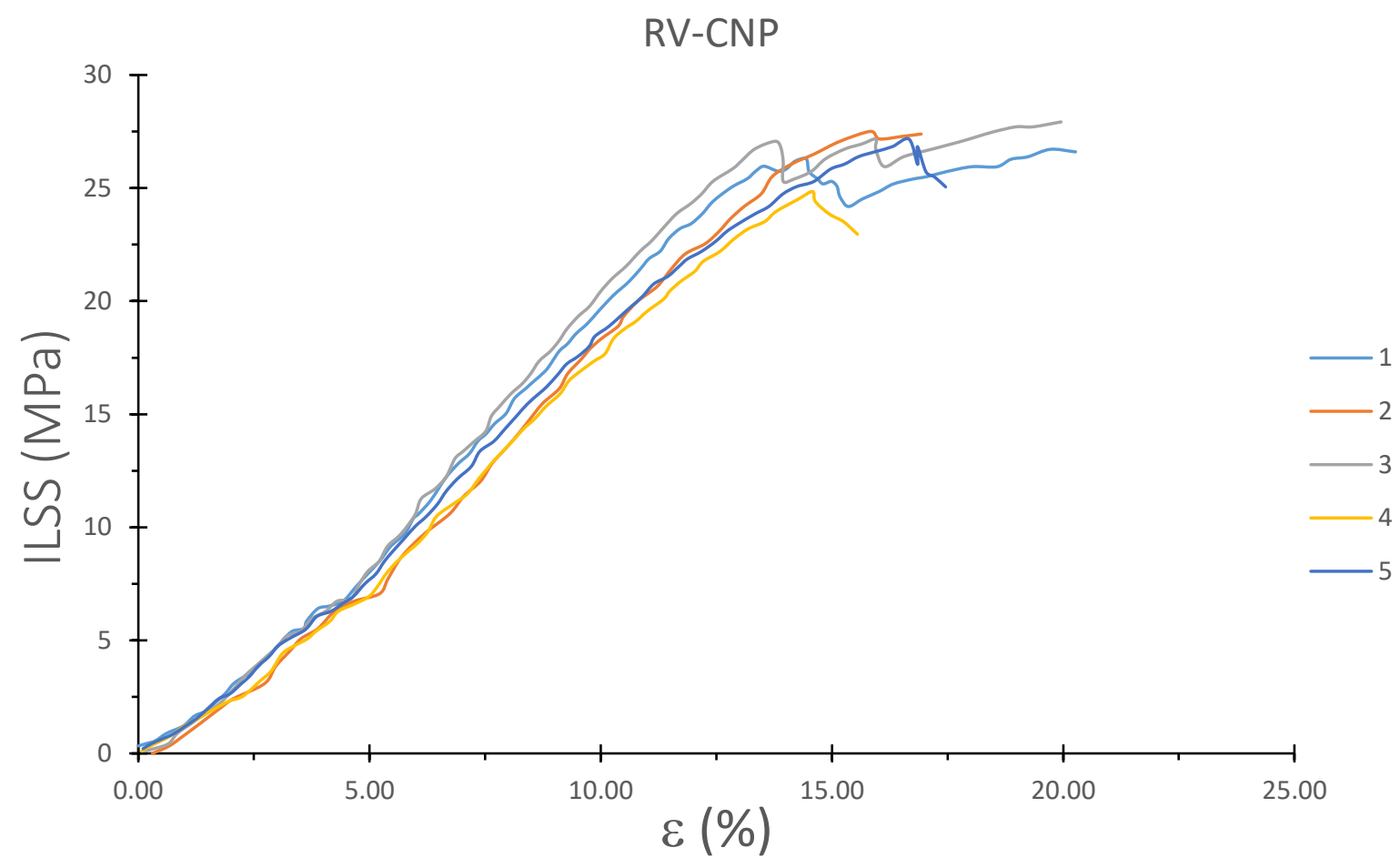

a)

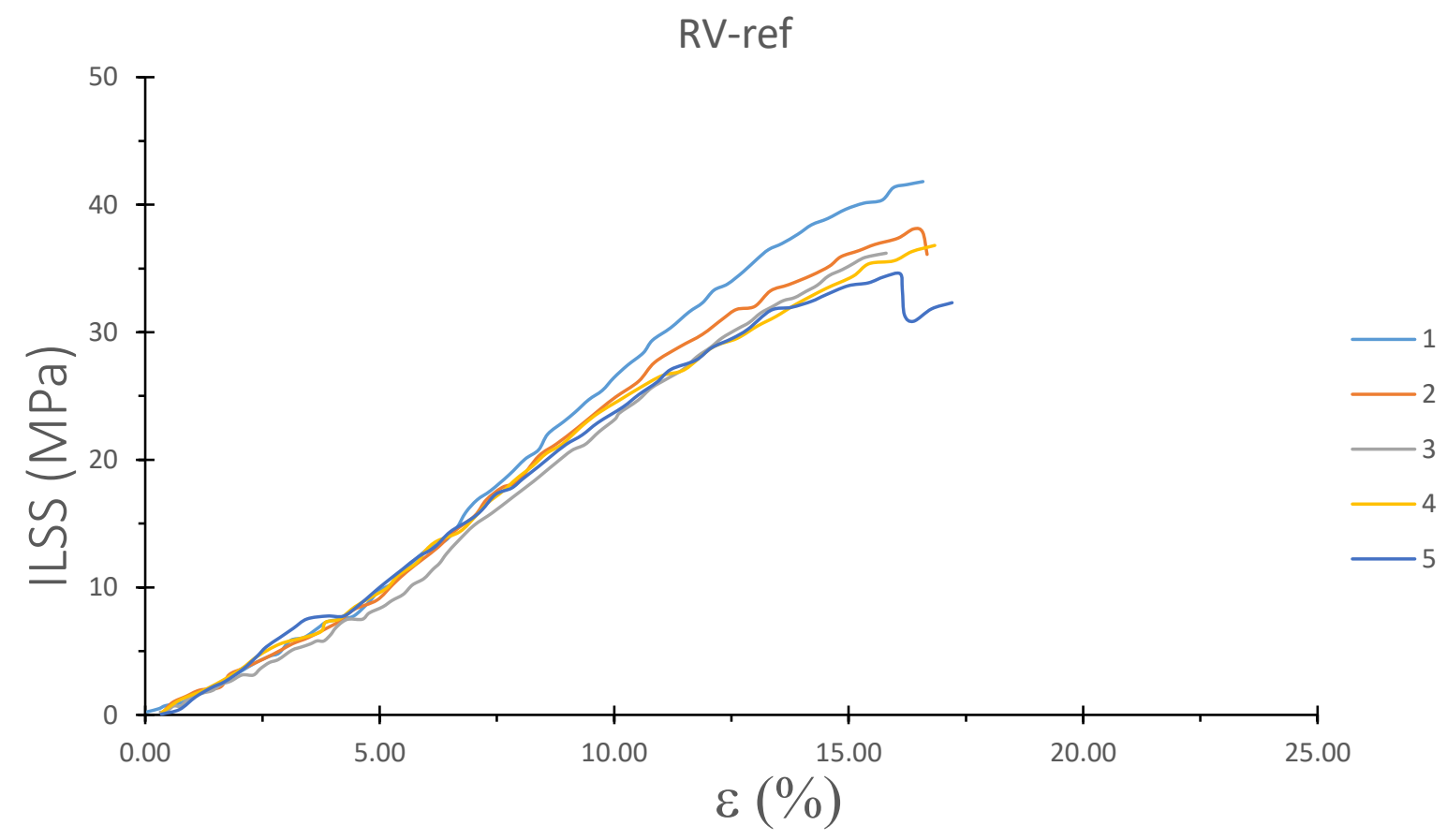

b)

Figure 12 - Stress - strain $(\varepsilon)$ curves in interlaminar shear strength test for Resin Impregnation Vacuum samples: (a) RV-CNP; (b) RV-ref 


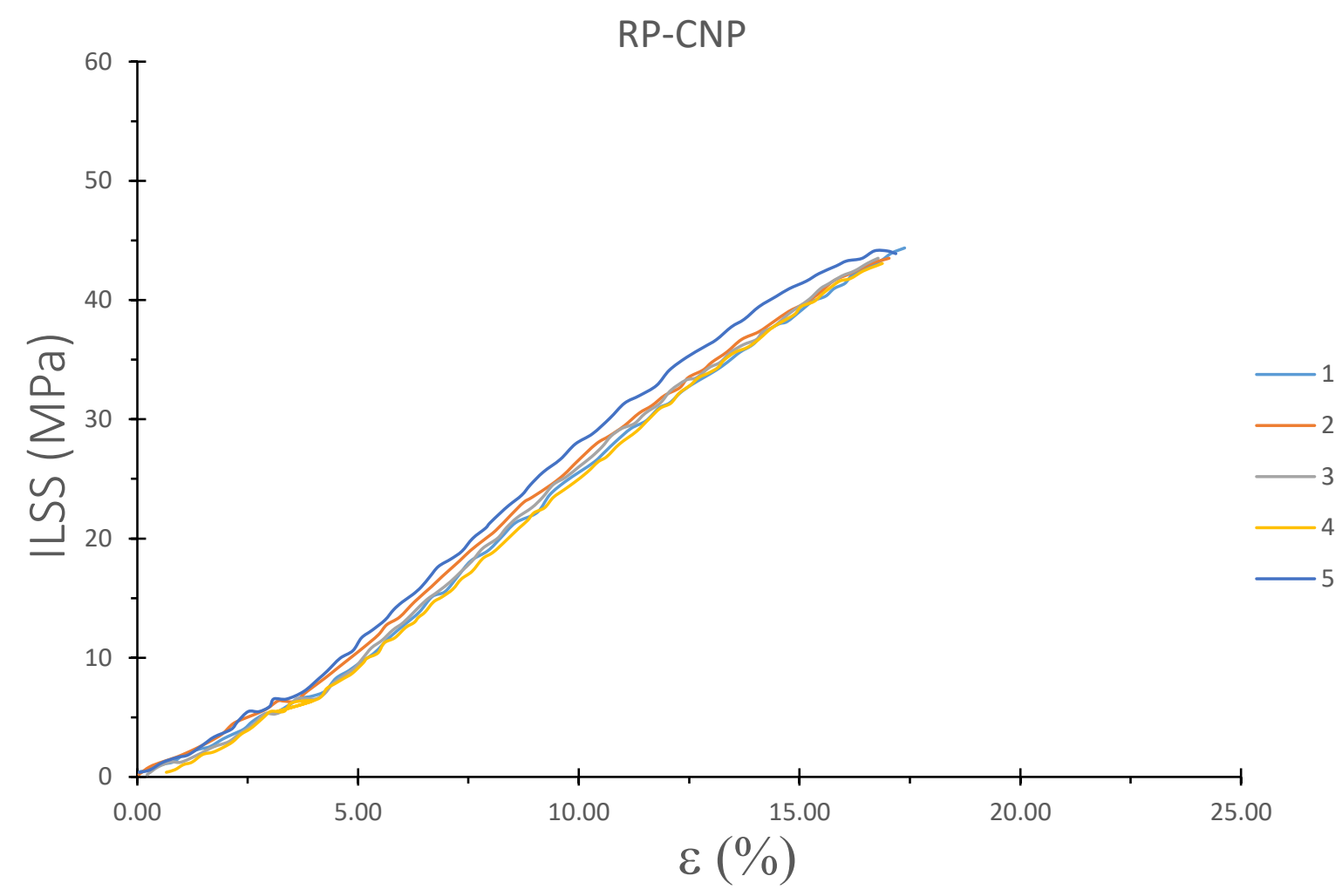

a)

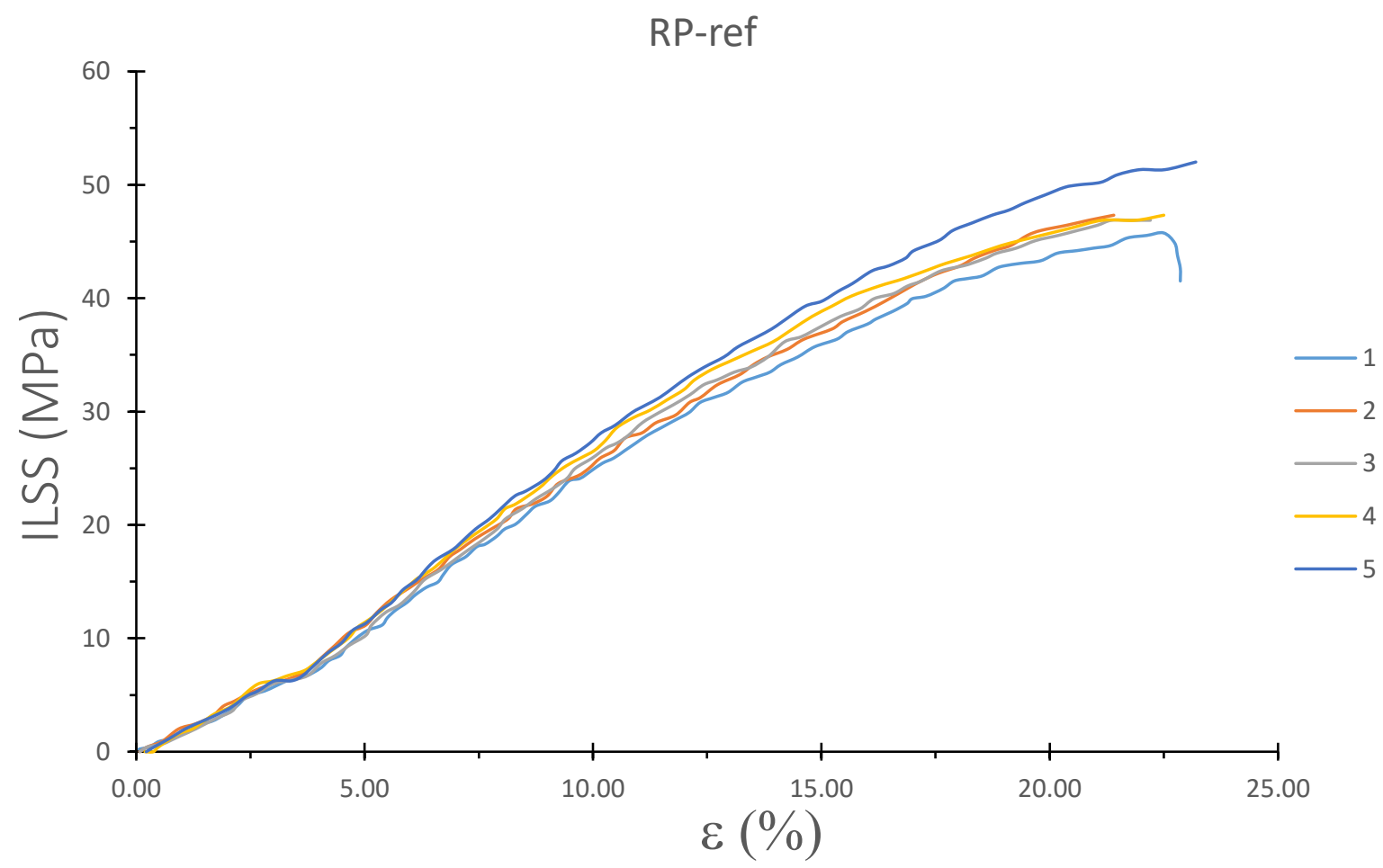

b)

Figure 13 - Stress - strain $(\varepsilon)$ curves in interlaminar shear strength test for Resin Impregnation Pressure samples: (a) RP-CNP; (b) RP-ref 


\section{Conclusions}

In this work, carbon nanotubes buckypapers embedded in fibre reinforced polymer composites have been fabricated by two processing approaches. Their electrical and mechanical properties were investigated. The first approach was the resin impregnation method, in which the CNPs were soaked in Araldite MY750. The second approach was the pre-preg method, where the buckypapers were layered between cyanate ester pre-preg plies.

The electrical resistance tests showed that both methods produced samples with electrical resistance lower than $5 \Omega$. In the pre-preg method, the resin did not affect the electrical resistance, but its amount was not enough to completely impregnate the CNTs sheets and bond the layers together, leading thus to delamination that occurred along the interface between the two CNPs. In the resin impregnation method, the use of pressure during curing was much effective to minimize the porosity and improve the consolidation of the composite material when compared with vacuum bag only approach.

The heating performance and ice protection tests showed power density values of around $2 \mathrm{~kW} / \mathrm{m}^{2}$, values well within the literature reported values. Lower voltages could be used, which would increase the ice melting time, but on the other hand would reduce the risk of thermal damage of the composite structure. Power density values could be increased by further reduction of the electrical resistance of the CNTs composite.

Flexural and ILSS tests show that in RP (resin impregnation pressure method) process the buckypaper did not weaken the mechanical characteristics. The pressure during curing cycle helped to create a stronger consolidation between the buckypapers and the matrix resin. The overall results indicate that RP method is an ideal process to fabricate the CNP-based selfheating composite.

A further study is recommended to optimize the design and the manufacturing process of the self-heating composite, to increase the power density of the CNT modified structures and to integrate the new nanostructures in real dimension components.

\section{Acknowledgment}

This work is funded by the INNOVATIVE doctoral programme. The INNOVATIVE programme is partially funded by the Marie Curie Initial Training Networks (ITN) action (project number 665468) and partially by the Institute for Aerospace Technology (IAT) at the University of Nottingham. Meggitt Airframe Systems Division, UK is acknowledged for the 
supply of the materials and the instruments used in the placement. The placement was supported by Mr Mark Hancock, Mr Michael Sanders and Mr Nick Thompson. Kyoto Institute of Technology is acknowledged for the supply of the instruments used in the placement. The placement was supported by Prof. Pezzotti Giuseppe, Prof. Marin Elia and all the colleagues of the laboratory.

\section{References}

1. U.S. Department of Transportation FAA. Aviation Maintenance Technician Handbook. 2012; 1 - 2. Handbook.

2. Gent RW, Dart NP and Cansdale JT. Aircraft icing. Philosophical Transactions of the Royal Society of London Series A: Mathematical, Physical and Engineering Sciences 2000; 358: 2873-2911.

3. Dalili N, Edrisy A and Carriveau R. A review of surface engineering issues critical to wind turbine performance. Renewable and Sustainable Energy Reviews 2009; 13: 428-438.

4. Amendola A and Mingione G. On the problem of icing for modern civil aircraft. Air \& Space Europe 2001; 3: 214-217.

5. Goraj Z. An overview of the deicing and anti-icing technologies with prospects for the future. In: 24th International Congress of the Aeronautical Sciences 2004.

6. Parent $\mathrm{O}$ and Ilinca A. Anti-icing and de-icing techniques for wind turbines: Critical review. Cold Regions Science and Technology 2011; 65: 88-96.

7. Hung $\mathrm{C}-\mathrm{C}$, Dillehay ME and Stahl M. A heater made from graphite composite material for potential deicingapplication. Journal of Aircraft 1987; 24: 725-730.

8. De Volder MF, Tawfick SH, Baughman RH, et al. Carbon nanotubes: present and future commercial applications. science 2013; 339: 535-539.

9. Thostenson ET, Li C and Chou T-W. Nanocomposites in context. Composites Science and Technology 2005; 65: 491-516.

10.Chou T-W, Gao L, Thostenson ET, et al. An assessment of the science and technology of carbon nanotube-based fibers and composites. Composites Science and Technology 2010; 70: 1-19.

11.Coleman JN, Khan U, Blau WJ, et al. Small but strong: a review of the mechanical properties of carbon nanotube-polymer composites. Carbon 2006; 44: 1624-1652.

12.Mohseni M. Development of a novel electro-thermal anti-icing system for fiber-reinforced polymer composite airfoils. University of Alberta, 2012.

13.Sorensen KL, Helland AS and Johansen TA. Carbon nanomaterial-based wing temperature control system for in-flight anti-icing and de-icing of unmanned aerial vehicles. In: Aerospace Conference, 2015 IEEE 2015, pp.1-6. IEEE.

14. Karapappas $P$, Tsotra $P$ and Scobbie K. Effect of nanofillers on the properties of a state of the art epoxy gelcoat. Express Polymer Letters 2011; 5.

15.Raji A-RO, Varadhachary T, Nan K, et al. Composites of Graphene Nanoribbon Stacks and Epoxy for Joule Heating and Deicing of Surfaces. ACS applied materials \& interfaces 2016; 8: 3551-3556.

16.Kandare $E$, Khatibi AA, Yoo S, et al. Improving the through-thickness thermal and electrical conductivity of carbon fibre/epoxy laminates by exploiting synergy between graphene and silver nano-inclusions. Composites Part A: Applied Science and Manufacturing 2015; 69: 72-82.

17.Gohardani O, Elola MC and Elizetxea C. Potential and prospective implementation of carbon nanotubes on next generation aircraft and space vehicles: A review of current and expected applications in aerospace sciences. Progress in Aerospace Sciences 2014; 70: 42-68.

18.Chu H, Zhang Z, Liu Y, et al. Self-heating fiber reinforced polymer composite using meso/macropore carbon nanotube paper and its application in deicing. Carbon 2014; 66: 154163. 
19.Zhao W, Li M, Zhang Z, et al. Carbon nanotube based composites film heater for de-icing application. In: 14th European Conference on Composite Materials 2010.

20.Coleman JN, Blau WJ, Dalton AB, et al. Improving the mechanical properties of single-walled carbon nanotube sheets by intercalation of polymeric adhesives. Applied Physics Letters 2003; 82: 1682-1684.

21.Wang Z, Liang Z, Wang B, et al. Processing and property investigation of single-walled carbon nanotube (SWNT) buckypaper/epoxy resin matrix nanocomposites. Composites Part A: applied science and manufacturing 2004; 35: 1225-1232.

22.Yao X, Hawkins SC and Falzon BG. An advanced anti-icing/de-icing system utilizing highly aligned carbon nanotube webs. Carbon 2018; 136: 130-138.

23.Tarfaoui M, El Moumen A, Boehle M, et al. Self-heating and deicing epoxy/glass fiber based carbon nanotubes buckypaper composite. Journal of materials science 2019; 54: 1351-1362.

24.Curtis P. CRAG (Composite Research Advisory Group) Test Methods for the Measurement of the Engineering Properties of Fibre Reinforced Plastics. 1988. ROYAL AEROSPACE ESTABLISHMENT FARNBOROUGH (UNITED KINGDOM).

25. Rosca ID and Hoa SV. Highly conductive multiwall carbon nanotube and epoxy composites produced by three-roll milling. Carbon 2009; 47: 1958-1968.

26.Song YS and Youn JR. Influence of dispersion states of carbon nanotubes on physical properties of epoxy nanocomposites. Carbon 2005; 43: 1378-1385.

27. Byrne MT and Gun'ko YK. Recent advances in research on carbon nanotube-polymer composites. Advanced materials 2010; 22: 1672-1688.

28.Kim YJ, Shin TS, Do Choi H, et al. Electrical conductivity of chemically modified multiwalled carbon nanotube/epoxy composites. Carbon 2005; 43: 23-30.

29.Su Y, Zhang S, Zhang X, et al. Preparation and properties of carbon nanotubes/carbon fiber/poly (ether ether ketone) multiscale composites. Composites Part A: Applied Science and Manufacturing 2018; 108: 89-98. 